Prepared for the U.S. Department of Energy

under Contract DE-AC05-76RL01830

\title{
Conceptual Model of Offshore Wind Environmental Risk Evaluation System
}

\section{Environmental Effects of Offshore Wind Energy} Fiscal Year 2010

RM Anderson

AE Copping

FB Van Cleve
SD Unwin

EL Hamilton

June 2010

Pacific Northwest

NATIONAL LABORATORY

Proudly Operated by Battelle Since 1965 


\title{
Conceptual Model of Offshore Wind Environmental Risk Evaluation System
}

\section{Environmental Effects of Offshore Wind Energy Fiscal Year 2010}

\author{
RM Anderson SD Unwin \\ AE Copping EL Hamilton \\ FB Van Cleve
}

June 2010

Prepared for

the U.S. Department of Energy

under Contract DE-AC05-76RL01830

Pacific Northwest National Laboratory

Richland, Washington 99352 



\section{Summary}

In this report we describe the development of the Environmental Risk Evaluation System (ERES), a risk-informed analytical process for estimating the environmental risks associated with the construction and operation of offshore wind energy generation projects. The development of ERES for offshore wind is closely allied with a concurrent process undertaken to examine environmental effects of marine and hydrokinetic (MHK) energy generation, although specific risk-relevant attributes will differ between the MHK and offshore wind domains.

During fiscal year 2010, a conceptual design of ERES for offshore wind will be developed. The offshore wind ERES mockup described in this report will provide a preview of the functionality of a fully developed risk evaluation system that will use risk assessment techniques to determine priority stressors on aquatic organisms and environments from specific technology aspects, identify key uncertainties underlying high-risk issues, compile a wide-range of data types in an innovative and flexible data organizing scheme, and inform planning and decision processes with a transparent and technically robust decision-support tool. A fully functional version of ERES for offshore wind will be developed in a subsequent phase of the project. 


\section{Acronyms and Abbreviations}

$\begin{array}{ll}\text { DOE } & \text { U.S. Department of Energy } \\ \text { ERES } & \text { Environmental Risk Evaluation System } \\ \text { FY } & \text { fiscal year } \\ \text { GIS } & \text { geographic information system } \\ \text { GPS } & \text { Global Positioning System } \\ \text { KMS } & \text { knowledge management system } \\ \text { MHK } & \text { marine and hydrokinetic } \\ \text { PNNL } & \text { Pacific Northwest National Laboratory }\end{array}$




\section{Contents}

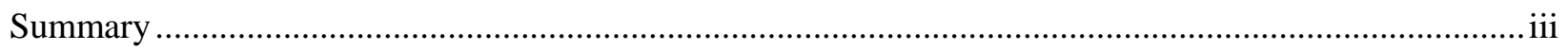

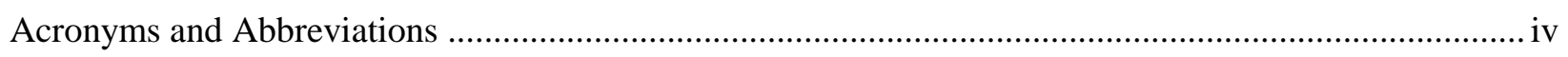

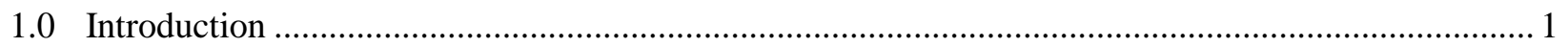

2.0 Conceptual Design of the Risk-Informed Decision Support Framework ......................................... 1

3.0 Risk Evaluation Process for Offshore Wind............................................................................. 3

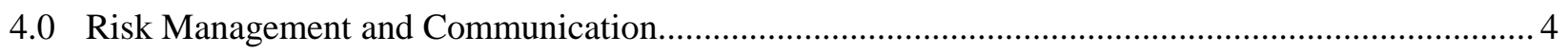

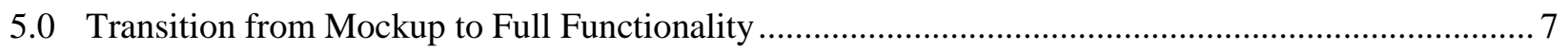

\section{Figures}

1 Relationship between the marine and hydrokinetic (MHK) and offshore wind environmental risk evaluation systems and knowledge management systems .................................................. 2

2 Stylized example of the ERES user interface .................................................................. 5

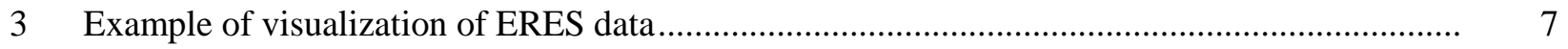

\section{Table}

1 Steps and outcomes for offshore wind ERES development 



\subsection{Introduction}

The Wind and Water Power Program of the U.S. Department of Energy (DOE) Office of Energy Efficiency and Renewable Energy is working with wind industry partners to develop clean, domestic, innovative wind energy technologies. The generation of energy from offshore wind has the potential to play a significant role in the nation's renewables portfolio. The first U.S. offshore wind farm has recently been granted rights to develop off the Atlantic coast; to date, no offshore wind farms have been developed. It is commonly believed that the lack of information on potential environmental impacts from the installation and operation of the facilities has slowed and confounded regulatory processes for moving forward efficiently on offshore wind development in the United States.

Pacific Northwest National Laboratory (PNNL) plans to evaluate the available information on environmental impacts from the installation and operation of offshore wind farms through the design and application of a risk framework entitled the Environmental Risk Evaluation System (ERES). The application of ERES and the specific decision-support tools developed to evaluate environmental effects of offshore wind will address the most important issues, risk categories, and information needs identified by stakeholders. During fiscal year (FY) 2010, a conceptual design of ERES for offshore wind will be developed. A visualization interface that will display output from ERES will be outlined, and a mockup created to demonstrate the usage and utility of the approach. A fully functional version of ERES for offshore wind will be developed in a subsequent phase of the project. Stakeholder input as well as guidance from the DOE Wind Program will be solicited in developing the design and specifications for this future version.

\subsection{Conceptual Design of the Risk-Informed Decision Support Framework}

The development of the ERES for offshore wind is closely allied with the process undertaken to examine environmental effects of marine and hydrokinetic (MHK) energy generation, although specific risk-relevant attributes will differ between the MHK and offshore wind domains. For both offshore wind and MHK, the ERES is tied closely to a knowledge management system (see below). The following description of the design of the ERES provides the overall concepts, while later sections address the specific application of the ERES for offshore wind.

Development and Application of ERES for Water Power. The concept for the ERES has been developed for application to MHK energy generation under the DOE Water Power program. As the U.S. MHK industry moves forward to deploy pilot, demonstration and commercial projects in coastal waters, concerns from regulators and stakeholders have focused on potential threats to marine life and to existing beneficial uses of marine waters. The ERES is under development to evaluate the relative risks of the many potential interactions between stressors (i.e., MHK systems and their component parts) and receptors in the marine environment (i.e., organisms such as marine mammals, fish, turtles, diving birds, as well as the waterbodies themselves through deteriorating water quality or changes in sediment transport). 
The tools and processes developed under the ERES will be common between MHK and offshore wind, while the application of those tools, the specific risk models, and the outputs of the two renewable energy sources will be distinct. In addition, the cases, tools, and processes of the ERES developed for MHK and offshore wind can be disassociated from one another at any time if necessary or desirable.

Knowledge Management System. A knowledge management system (KMS) has been created for MHK to organize and manage data and information for the ERES. This KMS is called Tethys, after the mythical Greek titaness of the sea. We propose to develop a parallel KMS named Zephyrus, after the Greek god of the west wind, to house and organize offshore wind environmental effects data. There are obvious crossovers between MHK environmental effects and those for offshore wind, notably the effect that wind platforms or wave buoys have on animals and physical processes in the ocean. In addition, many effects will be peculiar to offshore wind, most notably the effect that the rotors will have on migratory seabirds and perhaps bats. To best accommodate the needs of MHK and offshore wind, portions of the KMS will be shared, while other portions will contain data used only for one or the other renewable energy source. However, the structure of the KMS will allow separation of the MHK and offshore wind databases and all their relevant content at any time, if that becomes necessary or desirable.

The primary function of a KMS is to facilitate the creation, annotation, and exchange of information on environmental effects of offshore wind technology. The offshore wind KMS would be populated with data from multiple sources, including existing pilot and commercial offshore wind projects from the United States and abroad, from targeted environmental studies supported by DOE and other sources, and data generated by PNNL, other national laboratories, and universities. Data will eventually include tabular and geospatial data, text-based electronic documents, maps and geographic information system (GIS) layers, photographs, engineering drawings and specifications, technology descriptions, and demographic data. Figure 1 shows the similarities and differences between ERES processes for MHK and offshore wind.

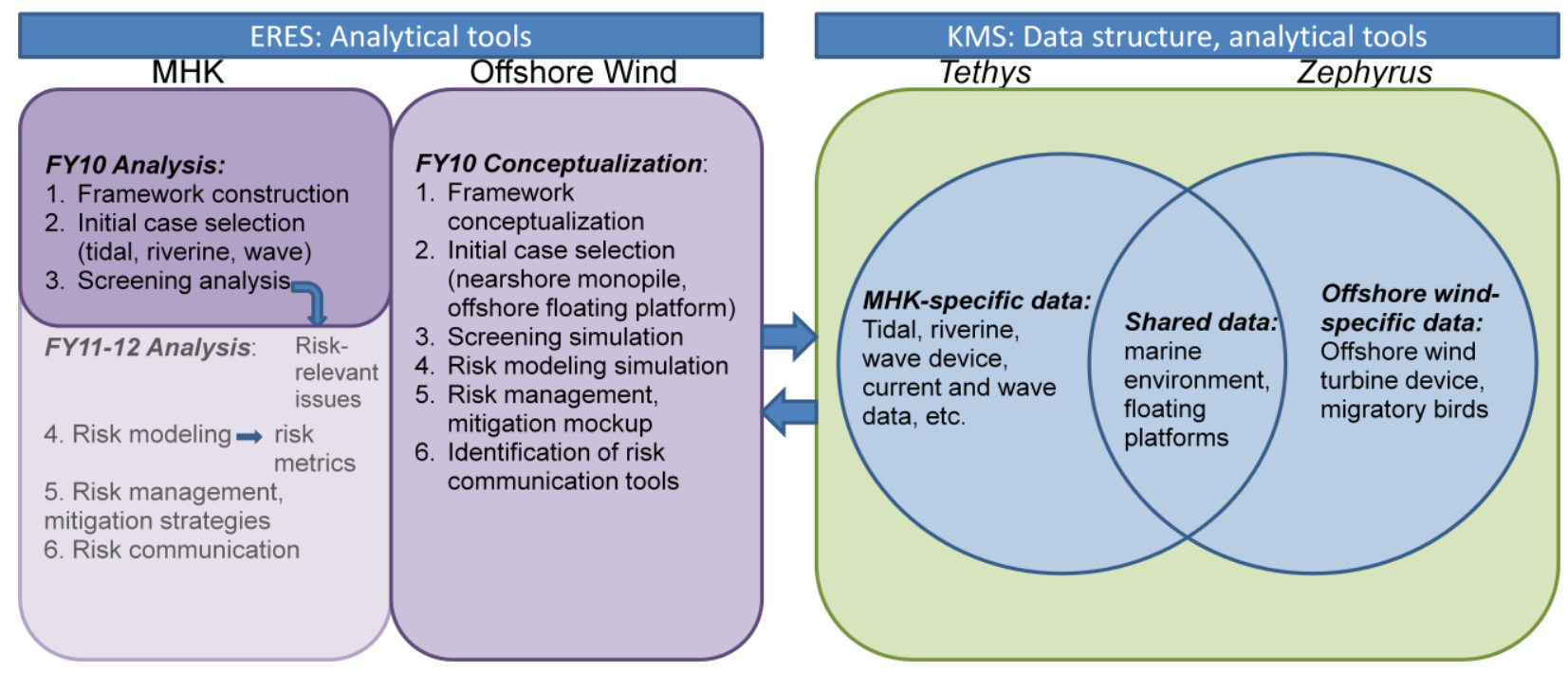

Figure 1. Relationship between the marine and hydrokinetic (MHK) and offshore wind environmental risk evaluation systems and knowledge management systems. 
Table 1 provides a conceptual representation of the process of developing the ERES and the KMS for offshore wind and MHK. Risk analysis steps include identification of analysis cases, risk analysis screening to identify highest risk-relevant issues, and risk modeling to estimate risk metrics for riskrelevant stressor-receptor interactions. The risk metrics will be used to develop risk management and mitigation strategies and to communicate those risks.

Table 1. Steps and outcomes for offshore wind ERES development.

\begin{tabular}{|l|l|l|l|l|}
\hline Steps & Purpose & Inputs & Outputs & FY10 \\
\hline $\begin{array}{l}\text { 1. ERES framework } \\
\text { development }\end{array}$ & $\begin{array}{l}\text { Definition of } \\
\text { domain for risk- } \\
\text { relevant factors }\end{array}$ & $\begin{array}{l}\text { Stressor, receptor, } \\
\text { and context data }\end{array}$ & $\begin{array}{l}\text { Risk-relevant } \\
\text { attributes }\end{array}$ & $\begin{array}{l}\text { Conceptual } \\
\text { description }\end{array}$ \\
\hline $\begin{array}{l}\text { 2. Initial case } \\
\text { selection }\end{array}$ & $\begin{array}{l}\text { Priorities include } \\
\text { "spanning the } \\
\text { analytical space" }\end{array}$ & $\begin{array}{l}\text { Project info, } \\
\text { selection criteria }\end{array}$ & $\begin{array}{l}\text { 3 initial cases } \\
\text { selected for } \\
\text { analysis }\end{array}$ & $\begin{array}{l}\text { Conceptual } \\
\text { description }\end{array}$ \\
\hline $\begin{array}{l}\text { 3. Screening } \\
\text { analysis on initial } \\
\text { cases }\end{array}$ & $\begin{array}{l}\text { Highest risk issues } \\
\text { identified }\end{array}$ & $\begin{array}{l}\text { Data for } \\
\text { verification }\end{array}$ & $\begin{array}{l}\text { Risk-relevant } \\
\text { issues }\end{array}$ & $\begin{array}{l}\text { Conceptual } \\
\text { description, } \\
\text { description of } \\
\text { analytical tools, } \\
\text { linkage to KMS }\end{array}$ \\
\hline 4. Risk modeling & $\begin{array}{l}\text { Cumulative risk } \\
\text { output calculated }\end{array}$ & $\begin{array}{l}\text { Deterministic, } \\
\text { probabilistic, } \\
\text { impact models, } \\
\text { sensitivity analysis }\end{array}$ & $\begin{array}{l}\text { Risk metrics that } \\
\text { relate each } \\
\text { stressor to } \\
\text { receptor }\end{array}$ & $\begin{array}{l}\text { Conceptual } \\
\text { description, } \\
\text { description of } \\
\text { analytical tools, } \\
\text { linkage to KMS }\end{array}$ \\
\hline $\begin{array}{l}\text { 5. Risk } \\
\text { management and } \\
\text { mitigation }\end{array}$ & $\begin{array}{l}\text { Strategies } \\
\text { developed, verified } \\
\text { by field data }\end{array}$ & $\begin{array}{l}\text { Risk-relevant } \\
\text { issues, risk metrics }\end{array}$ & $\begin{array}{l}\text { Risk mitigation } \\
\text { strategies }\end{array}$ & $\begin{array}{l}\text { Conceptual } \\
\text { description }\end{array}$ \\
\hline $\begin{array}{l}\text { 6. Risk } \\
\text { communication }\end{array}$ & $\begin{array}{l}\text { Risk and risk tools } \\
\text { presented in } \\
\text { formats accessible } \\
\text { to stakeholders }\end{array}$ & $\begin{array}{l}\text { Risk metrics, risk- } \\
\text { relevant issues }\end{array}$ & $\begin{array}{l}\text { Risk visualization, } \\
\text { communication } \\
\text { tools }\end{array}$ & $\begin{array}{l}\text { Conceptual } \\
\text { description, } \\
\text { mockup of } \\
\text { visualization tools }\end{array}$ \\
\hline
\end{tabular}

\subsection{Risk Evaluation Process for Offshore Wind}

The process for developing the ERES for offshore wind follows the six steps laid out in Table 1. Due to funding and schedule constraints, each step will consist of a limited mock up during FY10. Key portions of the ERES development include identifying and developing analytical tools to carry out screening analyses and risk modeling, developing risk management and mitigation strategies, and creating methods for risk communication.

Identifying or Creating Analytical Tools. Analytical tools that will be included in the ERES will be useful in performing risk- and decision-related analysis. Existing tools will be used where available and 
tools will be adapted or developed where necessary. Deterministic models may include detailed hydrodynamic models to examine circulation spatially and temporally in the vicinity of proposed wind farms. Probabilistic models will be used to understand other interactions such as collision risk for migrating birds at wind turbine rotor altitude. More complex models such as hydrodynamic models or models based on geographic information system (GIS) platforms will remain outside the ERES and be available as linked models. Tools that are locally available (embedded within the ERES) will perform simpler analyses based on spreadsheet functionality and other features. These will include tools to conduct sensitivity/what-if analyses, and functionality to perform Monte Carlo simulation. Visualization and animation tools will be applied to display risk communicative results.

The analytical tools will be applied to create estimates of risk; analysis outputs will be summarized and entered into the KMS. These results might include risk data sheets that list scenarios, impact severities, and measure(s) of uncertainty. As much as possible, these results will be spatially specific, including Global Positioning System (GPS) and/or latitude-longitude coordinates. Displays and animations created for risk communication will also be added to the KMS. These outputs might include cumulative distribution functions and risk contour maps.

Linking the KMS to the Analytical Tools. The KMS will be linked to the analytical tools as an evidence marshaling tool, allowing users to bring together disparate pieces of evidence (e.g., documents, database records, data values from tables, simulation results), in order to make them available as input parameters for risk models. This linkage from the KMS to the ERES will provide an unprecedented level of transparency in the use of data to support the analysis tools and risk outcomes.

In addition, outputs from the risk analyses, as well as supporting evidence provenance and other annotations, will be entered into the KMS, linking back to the input data files. This association of data will allow analysis results to be linked to specific candidate sites, geographic regions, site developers, or other attributes, creating patterns and linkages that may be of interest to the offshore wind stakeholder community.

\subsection{Risk Management and Communication}

Risk metrics will be used to develop risk management and mitigation strategies to address the most pressing issues identified in the study. Consultation with a wide range of stakeholders and regulatory agency staff will be necessary to develop acceptable mitigation strategies.

Outputs of the risk modeling within the ERES will be used to drive visualization, animation, and other displays to provide accessible outputs of the analyses. These visualizations will include ancillary environmental- and technology-related data as well as data of risk-relevance. Figure 2 provides an illustration of the functionality of the ERES user interface. The menu-driven structure allows users to select features that relate to the specific cases of interest from drop-down menus.

Different categories of users will use output data from ERES in different ways, constituting different "use cases". For example, MHK device developers and project developers may be most concerned with details of different technologies and wind farm geometries and the environmental risks each may pose. Regulators and researchers may be concerned with all the details of risk computations as well as the 
outputs and visualizations. Members of the interested public may be most concerned with the degree of impact expected and how those risks may affect them individually-for example, in terms of electricity costs, property values, and viewshed impacts.

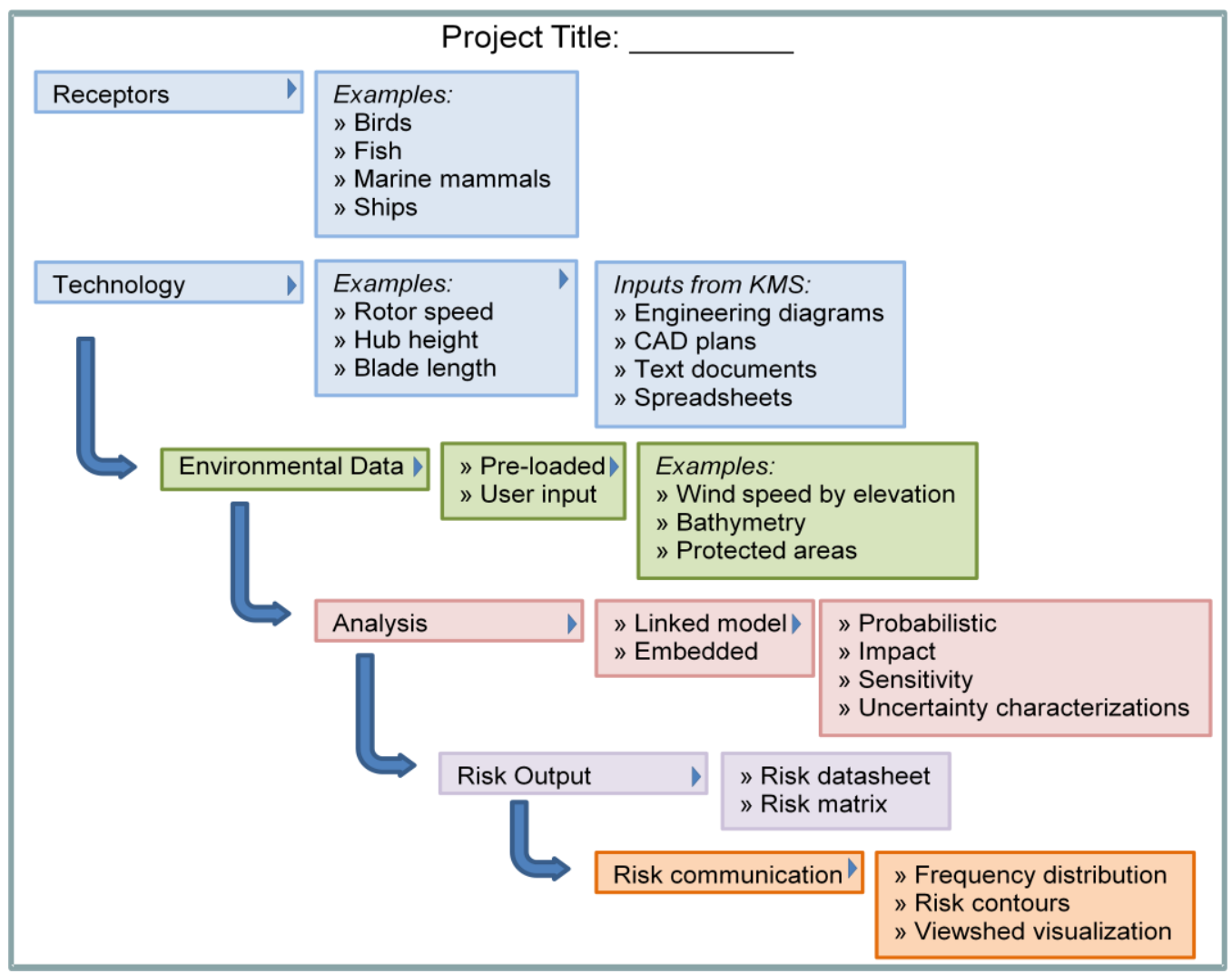

Figure 2. Stylized example of the ERES user interface. The boxes represent drop-down menus that will allow the user to interact with the ERES and KMS. The user would be able to customize a risk analysis by choosing specific case attributes (receptors or technologies) and environmental data, then applying analytical tools (risk models), customizing the outputs (risk datasheets or matrices), and specifying the communication products (visualization, cumulative frequency distributions).

Under the current project, a mockup of the visualization interface will be presented in the form of a series of PowerPoint slides. The mockup will represent selected modes of application of the ERES in a decision environment and will convey the overall vision for this risk-informed decision support tool. For the purposes of the mock up, three use cases will be defined; the themes that will be mocked-up for each case are outlined below.

\section{Developer Use Case:}

- different sizes and locations of wind farms

- different wind turbine generator technologies

- aggregated and disaggregated risk metrics (e.g., risk contours, cumulative distribution functions, measles chart, spatial dependence). 


\section{Regulator and Researcher Use Case:}

- model/analytical flow diagram

- knowledge management system

- multiple study comparisons

$\circ$ input uncertainty depiction

○ input characterization (time and space, metadata, other assumptions)

- environmental data (birds, whales, fish, winds, other)

- receptor data (bird migration routes, fish harvest activity, shipping lanes)

- complex model

- multiple model icons, model choice (e.g., bird/ship collision risk, viewscape visualization, noise propagation contours, electromagnetic field densities)

$\circ$ functionality of model(s)

○ output of model(s).

\section{Interested Public Use Case:}

- viewshed visualization

$\bigcirc$ alternative wind farm locations and sizes

$\circ$ alternative vantage points

- alternative visibility conditions

- social networking data, comment information.

As an example, Figure 3 displays environmental data on wind speed vs. elevation (e.g., regulator and researcher use case) as it could appear within the ERES software interface. This elementary example shows wind speeds over an ocean area at an elevation of $50 \mathrm{~m}$. The stippled areas show layouts for offshore wind farms at two locations, nearshore and in deeper water. The relative risk of deployment and environmental effects could be derived from applying the ERES tools to determine tradeoffs between the increased cost of deploying farther from shore and capturing the stronger winds. 


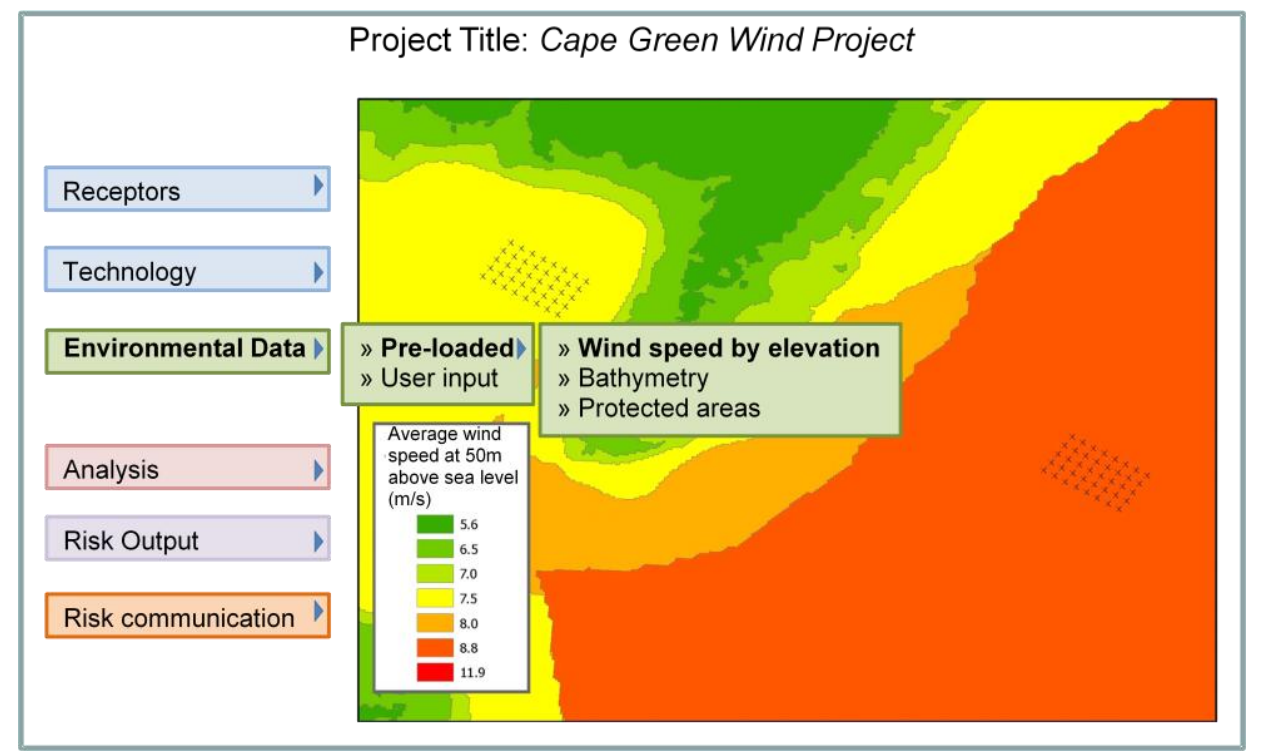

Figure 3. Example of visualization of ERES data.

\subsection{Transition from Mockup to Full Functionality}

The offshore wind ERES and KMS mockup described in this report will provide a preview of the functionality of a fully developed risk evaluation system that could be used to assess environmental risks associated with offshore wind energy development. The fully functional waterpower ERES and KMS will be developed by PNNL in the 2010-2012 fiscal years and will demonstrate capabilities of the system as it applies to MHK. For both water and wind power, when fully developed, the proposed risk evaluation system and associated KMS will use risk assessment techniques to determine priority stressors on aquatic organisms and environments from specific technology aspects, identify key uncertainties underlying high-risk issues, compile a wide range of data types in an innovative and flexible data organizing scheme, and inform planning and decision processes with a transparent and technically robust decision-support tool. 


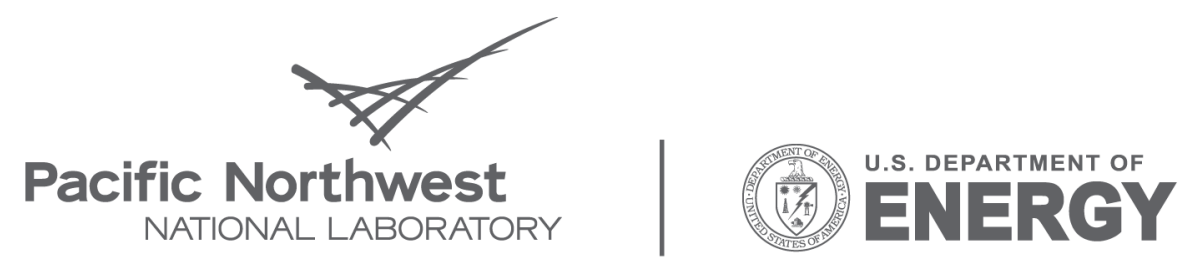

Proudly Operated by Battelle Since 1965

902 Battelle Boulevard

P.O. Box 999

Richland, WA 99352

1-888-375-PNNL (7665)

www.pnl.gov 